\title{
DETERMINATION OF TUNGSTEN INERT GAS WELDING INPUT PARAMETERS TO ATTAIN MAXIMUM TENSILE STRENGTH OF 316L AUSTENITIC STAINLESS STEEL
}

\author{
MOI Subhas Chandra ${ }^{1}$, PAL Pradip Kumar ${ }^{2}$, \\ BANDYOPADHYAY Asish ${ }^{3}$, RUDRAPATI Ramesh ${ }^{4}$ \\ Research Scholarl, Professor ${ }^{2,3}$, Assistant Professor ${ }^{4}$ \\ 1, 2,3 Jadavpur University, Department of Mechanical Engineering, Kolkata - 700032, India \\ e-mail:sc_moil@rediffmail.com ${ }^{1 *}$,pradippal54@yahoo.com ${ }^{2}$, asishbanerjee@yahoo.com ${ }^{3}$ \\ ${ }^{4}$ Hawassa University - Institute of Technology, Department of Mechanical Engineering, Hawassa - Ethiopia \\ e-mail: rameshrudrapati@gmail.com
}

\begin{abstract}
Weld quality mainly depends on the weld bead geometry and mechanical-metallurgical characteristics of the welded joint which has a direct relationship with the type of welding process being used and its input process parameters i.e. welding current, arc voltage, travel speed etc. In the present study, determination of tungsten inert gas (TIG) welding input parameters for achieving maximum tensile strength of $316 \mathrm{~L}$ austenitic stainless steel is investigated. Box-Behnken design of response surface methodology has been employed to formulate the experimental plan to identify the effect of process parameters on tensile strength. Square butt joint configuration has been made using three factors - three levels of welding input parameters. Joint strength has been evaluated by notch tensile strength (NTS) and Unnotch tensile strength (UTS) method and correlated with microstructure and micro hardness of the weld. The results indicate that gas flow rate has greater influence on both NTS and UTS followed by welding current.
\end{abstract}

KEYWORDS: TIG welding, response surface methodology, notched tensile strength, optimization, ANOVA.

\section{Introduction}

Welding is a permanent joining process that joins two or more materials, usually metals or thermoplastics with or without application of heat, pressure and filler materials. Tungsten inert gas welding is basically an electric arc welding process which uses non-consumable tungsten electrode and arc is established between the tip of an electrode and the work piece. Inert gas (argon, helium etc.) is used to avoid contamination of the weldment with air. Sometimes a mixture of any two of the gases mentioned above is also used. TIG welding is one of the most versatile welding processes that join almost all metals and metal alloys in use today. This welding process is very much favoured for its natural qualities like high-quality and superior welds, low distortion, narrow heat affected zone and it leaves no slag or splatter. TIG welding process is extensively used in the modern industries such as automobile industry, aircraft, nuclear industry, food processing industry, precision manufacturing industry, maintenance and repair work etc.

TIG welding is frequently used for fabrication of austenitic stainless steel. This stainless steel is usually found to be the most weldable due to its physical properties and welding activities compare to the other stainless steels. 316L austenitic stainless steel is one of the most important materials for industrial uses because of its natural qualities. It is a nonmagnetic material, cheaper in cost and easily available in the market. It possesses good mechanical properties like formability, ductility and weldability, toughness and high tensile 
strength at elevated temperature compare to other stainless steels [1]. 316L stainless steel belongs to 300 series grade of austenitic stainless steels. Here 'L' denotes an extra-low carbon version of austenitic stainless steel. This extra low carbon diminishes harmful carbide precipitation during welding.

Welding input process parameters play very important role in determining the quality or in other words, the mechanical properties which includes hardness, tensile strength, fatigue strength etc of the welded joint. Therefore, the proper choice of welding process parameters and its levels are very crucial for obtaining optimal mechanical properties [2, 3, 4, 5]. Welding current, arc voltage, electrode size, arc travel speed, electrode stick out etc are the important welding process parameters. Further, the quality of weld in TIG welding may be influenced due to welding position, electrode composition, edge preparation, the type of gas used and its flow rate.

From the literature review, Ragavendran et al. [6] have studied the effect of the hybrid laser-TIG welding process parameters on weld bead geometry of $316 \mathrm{LN}$ stainless steel using desirability approached optimization technique to obtain desired weld bead profile. There are different optimization techniques that can be used to determine the required output responses through the development of mathematical equations to postulate the relationships between the input parameters and output variables [7, 8]. One of the most widely used statistical methods of optimization is the response surface methodology (RSM), in which the researchers try to approximate the unknown mechanism with an appropriate empirical model $[9,10,11]$. Murugan and Parmer [12] established quadratic relationship between the parameters of MIG welding and parameters of weld pool geometry on $316 \mathrm{~L}$ austenitic stainless steel. Padmanaban at el. [13] investigated laser beam welding process through experiment in butt join configuration made by AZ31B magnesium alloy and optimized the process to obtain highest tensile strength. Chu et al. [14] investigated dissimilar laser welding of Ti-6Al-4V (Ti6-4) to Ti-4.5A1-3V-2Fe-2Mo (SP-700) alloys and joint strength was evaluated by notch tensile strength and correlated with microstructure and micro hardness. Anawa and Olabi [15] reported the optimization of notch tensile strength of dissimilar metals (ferritic and austenitic) by laser beam welding process. Taguchi method is used to formulate the experimental plan and results are analysed using ANOVA and signal to noise ratio for optimal parameters. Rajakumar et al. [16] investigated the effect of process parameters and tool parameters on the strength of the joint that is produced by friction stir welding of aluminium alloy. Selvamani and Palanikumar [17] established empirical relationships to predict ultimate tensile strength, notch tensile strength and percentage elongation of the welded joints made by friction welding of carbon steel. Micro hardness, microstructure, SEM are also studied and presented there. Srivastava and Garg [18] had carried out experimental analysis to study the effects of the welding process parameters on welding of mild steel plates using gas metal arc welding process by using Box Behnken design of response surface methodology. Ghosh et al. [19] applied Grey based Taguchi method on the experiment of MIG welding on 316L stainless steel. They concluded that the welding current is the most significant factor for obtaining highest joint strength. Lakshminarayanan et al. [20] had conducted comparative analysis among shielded metal arc welding, gas metal arc welding and gas tungsten arc welding processes to study the tensile and impact properties of the ferritic stainless steel of thickness 4 $\mathrm{mm}$. Researchers had been found from their study was that gas tungsten arc welding technique was found to be advantageous compared to other welding operations for joining ferritic stainless steels, due to the presence of finer grains in fusion zone and heat affected zone. Senthil Kumar et al. [21] reported the impact of pulsed current TIG welding parameters on the joint strength of AA 6061 aluminium alloy. It is concluded that the pulsed current parameters such as peak current and pulse frequency varies directly proportional to tensile 
properties. Lin et al. [22] experimentally drawn a comparison of mechanical properties such as tensile strength, impact strength etc. of pure copper welded using friction stir welding and tungsten inert gas welding. Joint strength evaluated by tensile strength and notch tensile strength. It is found the notch tensile strength and notch tensile ratio of friction weld are sufficiently higher than those of TIG welding.

It is noticed from literature survey that many investigators have been focused on various aspects of welded joints including micro structural analysis, analysis of mechanical properties such as tensile strength, impact toughness, fatigue strength, hardness and corrosion resistance of stainless steel. But very few research works have been reported to optimized tungsten inert gas welding parameters to obtain maximum strength in terms of notch tensile strength of $316 \mathrm{~L}$ austenitic stainless steel joints. As notches are very important factors in any structural materials/bodies and the existence of notches or in other words stress concentrations can depreciate the mechanical properties of a material. Therefore, in this study an attempt has been made to optimize TIG welding process parameters to attain maximum notch tensile strength, as well as unnotch tensile strength simultaneously in AISI 316L stainless steel using response surface methodology.

\section{Experimental procedures}

Stainless steel (AISI 316L) plates of size $100 \mathrm{~mm} \times 80 \mathrm{~mm} \times 3 \mathrm{~mm}$ have been selected as work piece material which is cut from a rolled sheet and ER316L austenitic stainless steel of diameter $1.6 \mathrm{~mm}$ has been taken as a filler material. The chemical composition of the base material and filler material is given in Table 1. The mechanical properties of the base metal are as follows: ultimate tensile strength $609 \mathrm{MPa}$, yield strength $307 \mathrm{MPa}$, modulus of elasticity $180 \mathrm{GPa}$ and hardness $202 \mathrm{VHN}$. The most influencing parameters which affect weld pool geometry or mechanical properties of TIG welded joints are identified through extensive literature survey and previous work done. The important identified process parameters are welding current, gas flow rate and welding speed. A large number of trials have been performed on $3 \mathrm{~mm}$ thick AISI 316L stainless steel plates to find out the efficient and practicable working limits of TIG welding parameters and this has been done by altering one of the selected parameters while others remains constant. The visual inspection and non destructive tests have been used to identify the working limits of the welding process parameters. Table 2 shows the identified welding parameters along with their three levels.

Table 1 Chemical composition of the base material, filler material and weld metal

\begin{tabular}{|l|c|c|c|c|c|c|c|c|c|c|}
\hline Weight \% & $\mathrm{C}$ & $\mathrm{Mn}$ & $\mathrm{Si}$ & $\mathrm{S}$ & $\mathrm{P}$ & $\mathrm{Cr}$ & $\mathrm{Ni}$ & $\mathrm{Mo}$ & $\mathrm{Cu}$ & $\mathrm{Fe}$ \\
\hline AISI 316L & 0.026 & 0.97 & 0.26 & 0.012 & 0.043 & 16.12 & 10.08 & 2.03 & 0.15 & 70.31 \\
\hline ER 316L & 0.040 & 1.50 & 0.45 & 0.030 & 0.030 & 18.20 & 12.00 & 2.30 & 0.75 & 64.70 \\
\hline Weld Metal & 0.031 & 1.41 & 0.33 & 0.021 & 0.034 & 17.23 & 10.88 & 2.23 & 0.42 & 67.41 \\
\hline
\end{tabular}

Table 2 TIG welding parameters and theirs levels

\begin{tabular}{|c|c|c|c|c|c|}
\hline Parameters & \multirow{2}{*}{ Units } & \multirow{2}{*}{ Notation } & \multicolumn{3}{|c|}{ Levels } \\
\cline { 4 - 6 } & & & -1 & 0 & +1 \\
\hline Welding current & $\mathrm{A}$ & $\mathrm{A}$ & 100 & 125 & 150 \\
\hline Travel Speed & $\mathrm{cm} / \mathrm{min}$ & $\mathrm{B}$ & 12 & 15 & 18 \\
\hline Gas flow Rate & $1 / \mathrm{min}$ & $\mathrm{C}$ & 6 & 9 & 12 \\
\hline
\end{tabular}

The statistical software Design Expert 11 is applied to develop the experimental plan according to Box- Behnken design technique of response surface methodology under varied input process parameters. The experimental design matrix is shown in Table 3 . The pictorial 
view of the experimental unit is shown in Fig. 1. Here, the TIG torch has been fixed to the travel car to confirm the torch is set at a predetermined angle. The travel car travels on the defined path and can move only straight line direction. Control of current, speed and gas flow rate are done by manually for each run. Square butt joint configurations have been prepared by SUPERGEN 320 TIG welding machine using argon with purity 99.99\%, as shielding gas. The welding direction has been taken as normal to the direction of rolling. To avoid distortion the work pieces have been placed on copper plate and mechanical clamps are also used during welding.

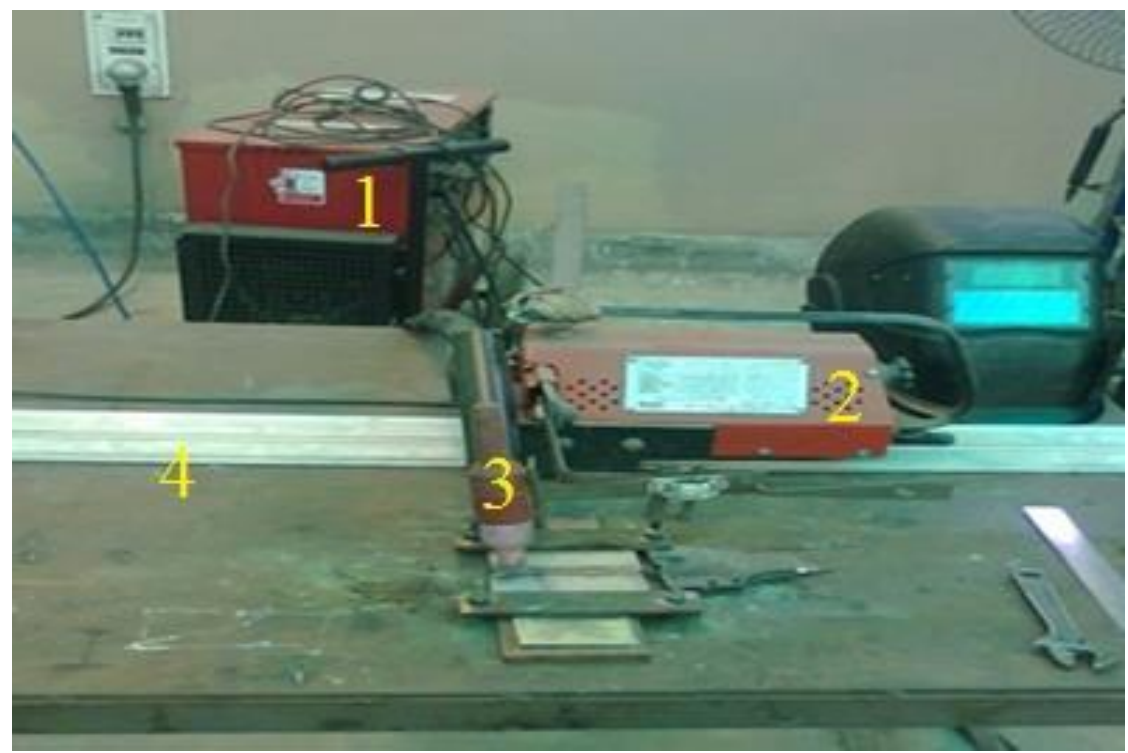

1-welding machine, 2-travel car, 3-TIG torch, 4- track

Fig. 1 Photographic view of experimental setup

Welding being done, all the samples are inspected visually. Some welding defects include: little undercut at the end, large reinforcement height, lack of penetration, porosity etc. are observed in few samples and these samples are sample no. 7, 8, 11. Under certain parametric conditions, almost no defects are found in a few samples namely sample no 5, 9, 12, 13, 14, and 15. Under cut defect may be caused by inappropriate joint geometry in some of the samples. It may have been resulted because of excessive welding current, and voltage. Lack of penetration is one of the main defects which will affect the joint strength of the welded sample. The reasons for lack of penetration are faster travel speed/ low heat input, incorrect selection of welding currents levels, improper cleaning of welding zone, and presence of oxides, scale and other impurities which do not allow the deposited metal to fuse accurately with the base metal [23]. Further, the skill of the operator or technician is very crucial for weld quality. Defects may come from any type of irregularities / inhomogenity in the base metal as well as filler wire. Photographic view of two welded specimens, sample number 1 and sample number 14 are shown in Fig. 2.

$\mathrm{X}$-ray radiography test has been conducted for all the 15 welded samples to determine the internal soundness after the visual inspection by XXQ-2005 X-Ray flaw detector. It is noticed that almost all the samples pass through X-ray radiography test with no significant defect remarks. Porosity, voids etc. has been found in few samples. Porosity may create when atmospheric gases are being entrapped in the solidifying metal. The causes of porosity may include lack of shielding gas or too much shielding gas, improper cleanness of the work piece etc. The images of X-ray radiography of two samples are shown in Fig. 3. 

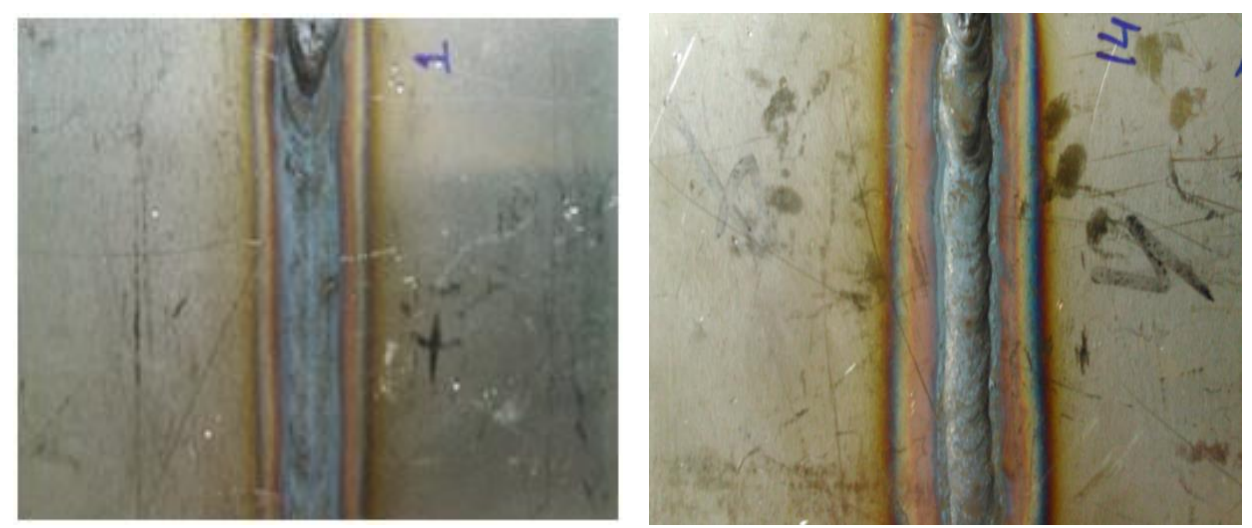

Fig. 2 Photographic view of welded sample number $1 \& 14$
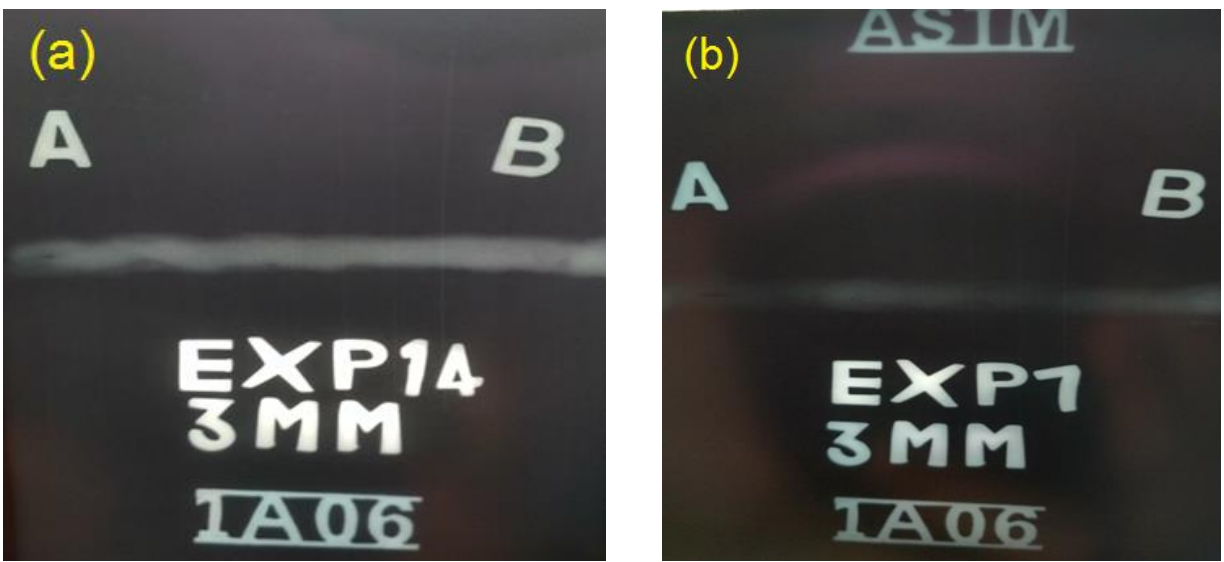

Fig. 3 Image of the X-ray radiography plate (a) sample-14 and (b) sample-7

After X-ray radiography test, all the welded joints are cut perpendicular to the direction of welding for metallographic examination by polishing and etching. Micro-hardness test is done using Vickers's micro-hardness testing machine on flat metallographic specimen across the joints of the weld. Two different types of tensile specimens, notched tensile specimens and smooth /unnotched tensile specimens have been prepared in accordance with ASTM E8M-04 as shown in Fig. 4(a) and Fig. 4(b) respectively. Tensile test has been conducted by Instron universal testing machine (Model- 8801 and capacity-100kN) at a strain rate of $0.001 / \mathrm{s}$ to evaluate notched tensile strength (NTS), unnotched tensile strength (UTS) and notch strength ratio (NSR) of base metal as well as TIG welded joints and obtained results are listed in the Table 3.

(a)
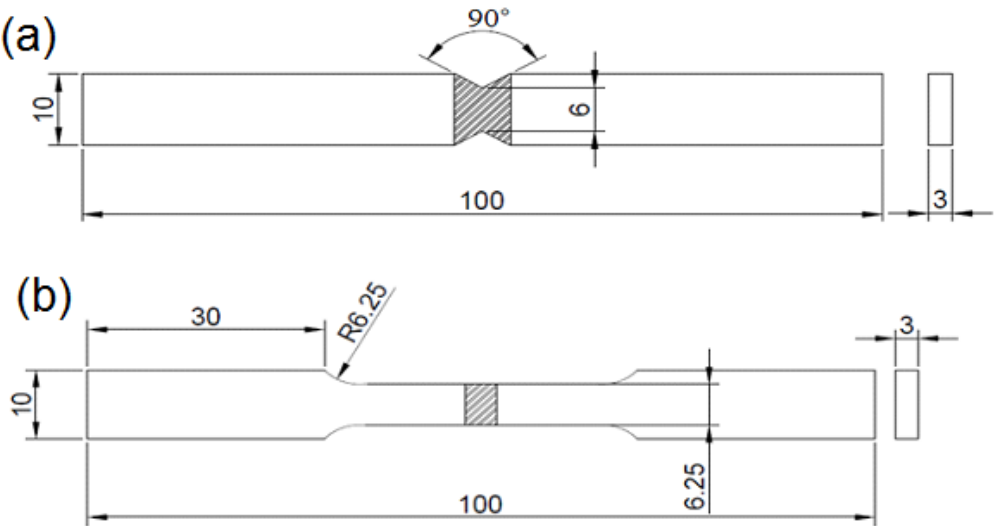

Fig. 4 TIG welded sample for tensile test (a) notched specimen (b) unnotched specimen

Table 3 Box-behnken design of RSM and output responses 


\begin{tabular}{|c|c|c|c|c|c|c|}
\hline \multirow{2}{*}{ Run } & \multicolumn{2}{|c|}{ Box-behnen design table } & \multicolumn{3}{c|}{ Output responses } \\
\cline { 2 - 7 } & $\begin{array}{c}\text { Current } \\
(\mathrm{A})\end{array}$ & $\begin{array}{c}\text { Speed } \\
(\mathrm{cm} / \mathrm{min})\end{array}$ & $\begin{array}{c}\text { GFR } \\
(\mathrm{l} / \mathrm{min})\end{array}$ & $\begin{array}{c}\text { NTS } \\
(\mathrm{MPa})\end{array}$ & $\begin{array}{c}\text { UTS } \\
(\mathrm{MPa})\end{array}$ & NTR \\
\hline 1 & 100 & 12 & 9 & 727.22 & 612.13 & 1.19 \\
\hline 2 & 150 & 12 & 9 & 728.42 & 616.42 & 1.18 \\
\hline 3 & 100 & 18 & 9 & 685.69 & 608.48 & 1.13 \\
\hline 4 & 150 & 18 & 9 & 736.75 & 631.37 & 1.17 \\
\hline 5 & 100 & 15 & 6 & 763.87 & 620.26 & 1.23 \\
\hline 6 & 150 & 15 & 6 & 731.54 & 612.91 & 1.19 \\
\hline 7 & 100 & 15 & 12 & 680.24 & 580.61 & 1.17 \\
\hline 8 & 150 & 15 & 12 & 752.32 & 610.69 & 1.23 \\
\hline 9 & 125 & 12 & 6 & 765.68 & 624.15 & 1.23 \\
\hline 10 & 125 & 18 & 6 & 709.94 & 616.24 & 1.15 \\
\hline 11 & 125 & 12 & 12 & 707.25 & 592.42 & 1.19 \\
\hline 12 & 125 & 18 & 12 & 721.65 & 615.88 & 1.17 \\
\hline 13 & 125 & 15 & 9 & 770.63 & 639.42 & 1.21 \\
\hline 14 & 125 & 15 & 9 & 783.27 & 642.64 & 1.22 \\
\hline 15 & 125 & 15 & 9 & 775.23 & 639.67 & 1.21 \\
\hline \multicolumn{3}{|c|}{ Base metal } & 658.45 & 608.88 & 1.08 \\
\hline
\end{tabular}

\section{Results and discussion}

\subsection{Micro structural analysis}

The microstructural study of all the welded samples along with base material has been carried out by both optical microscope (Make: Leica; Model: DLM2700M) and scanning electron microscope (SEM) (Make: JEOL; Model: JSM6360). But microstructures of only two specimens such as sample no.7 and sample no.14 and base metal are presented here. The selection of these samples for study is based on its performances on tensile test. Sample no.14 depicts maximum joint strength both NTS and UTS, where as sample no.7 shows minimum NTS and UTS.

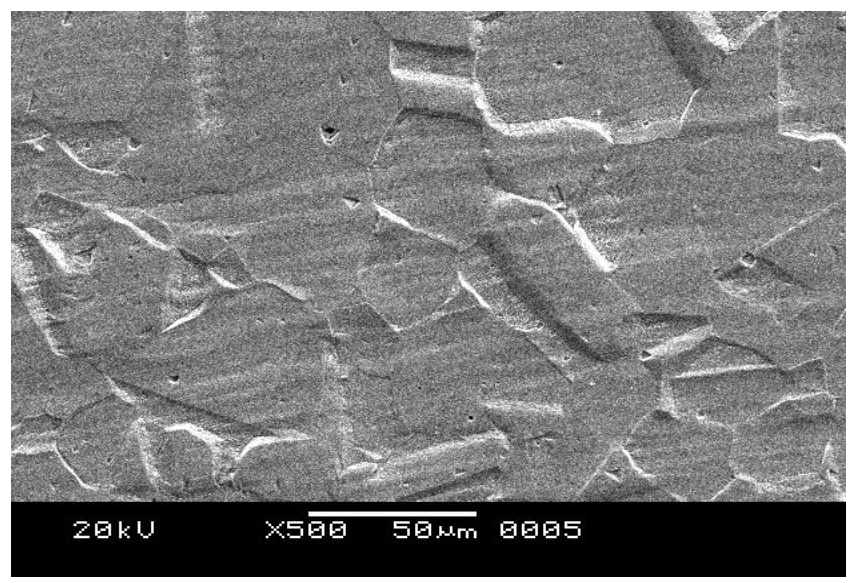

Fig. 5 SEM micrographs of base metal

Typical SEM micrograph of the base metal is shown in Fig. 5. Fully austenitic structure with little annealing twins is observed in base microstructure. Wichan and Loeshpahn [24] are also reported similar result. The optical microstructures of TIG welded joint and weld metal of the selected samples are represented in Figs. 6-7. The base metal (BM), heat affected zone 
(HAZ) and weld metal (WM) can be easily distinguished. The microstructure of these weld metals consists of ferrite and austenite i.e. $\delta$-ferrite structure that could be described by primary solidification modes of weld metals. The weld metal solidification mode can be explained by the $C r_{e q} / N i_{e q}$ ratio. The $C r_{e q} / N i_{e q}$ ratio is calculated using the Schaeffler formula [25]. In the present study the $C r_{e q} / N i_{e q}=1.59$ (chemical composition of weld metal is listed in Table 1). Therefore the solidification mode is ferritic-austenitic mode (FA) as $1.48 \leq C r_{e q} / N i_{e q} \leq 1.95$.

FA mode: $\mathrm{L} \rightarrow \mathrm{L}+\delta \rightarrow \mathrm{L}+\delta+\gamma \rightarrow \delta+\gamma \rightarrow \gamma: 1.48 \leq C r_{e q} / N i_{e q} \leq 1.95$

where $\mathrm{L}$ is the liquid, $\delta$ is delta-ferrite and $\gamma$ is austenite respectively

The weld zone of sample no. 14 exhibits a very fine skeletal $\delta$-ferrite along with grain, subgrain and migrated boundaries in plain austenitic matrix due to moderate heat input and moderate cooling rate. Sample no. 7 consists of $\delta$-ferrite in the form of dendritic lathy $\delta$-ferrite at the dendrite core surrounded by inter dendritic $\gamma$-phase due to low welding heat inputs, i.e. high cooling rates.
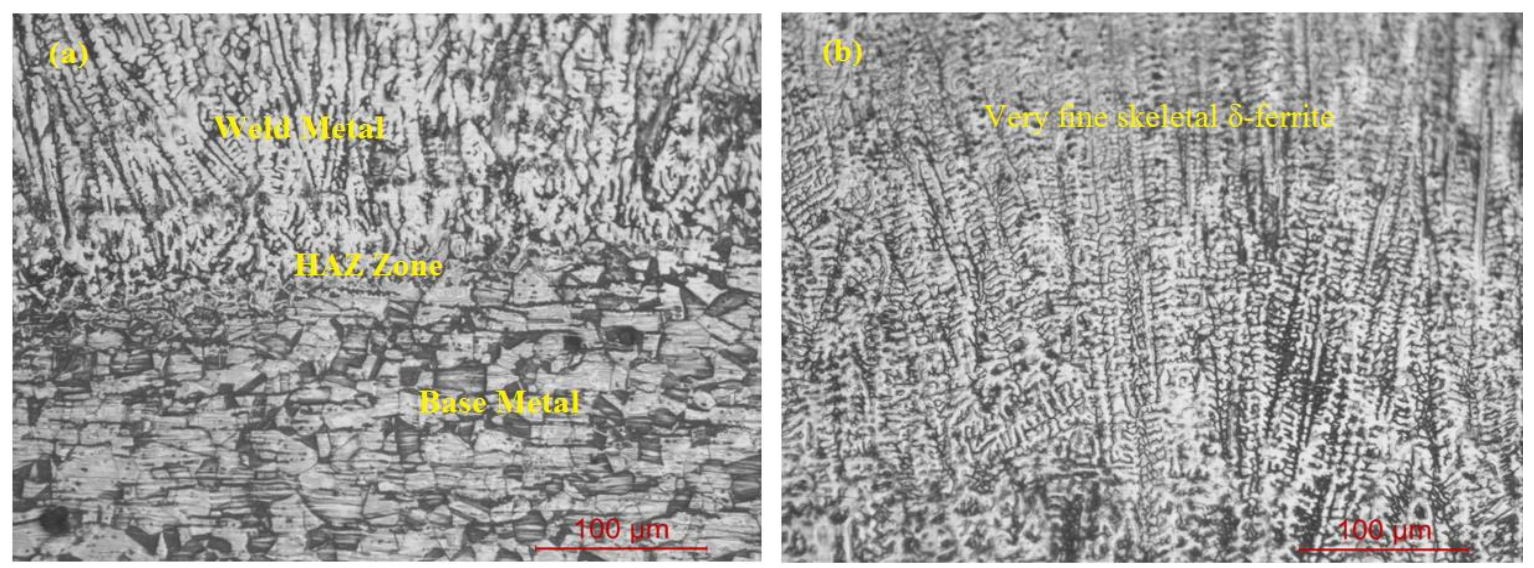

Fig. 6 Optical microstructures of sample no.14, (a) welded joint (b) weld metal
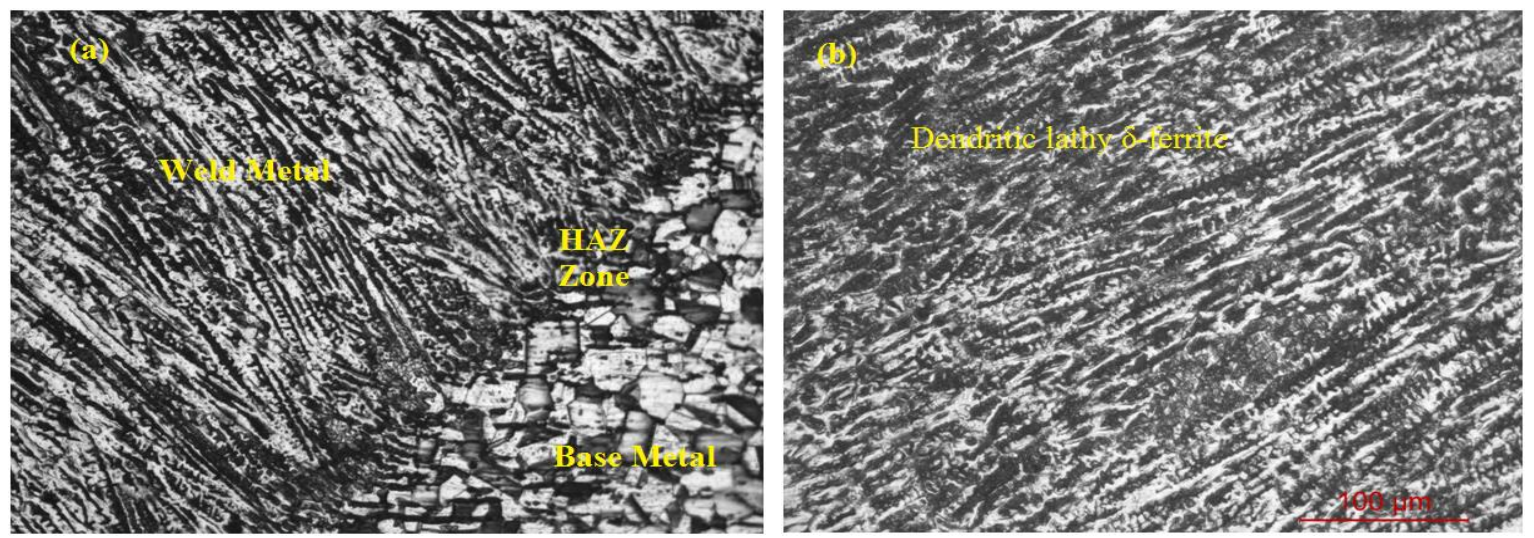

Fig. 7 Optical microstructures of sample no.7, (a) welded joint (b) weld metal

Fig. 8(a) and Fig.8(b) illustrate the SEM micrographs of weld zone of the specimen no.14 and specimen no.7 respectively. Both optical and SEM micrographs exhibit similar types of results. 

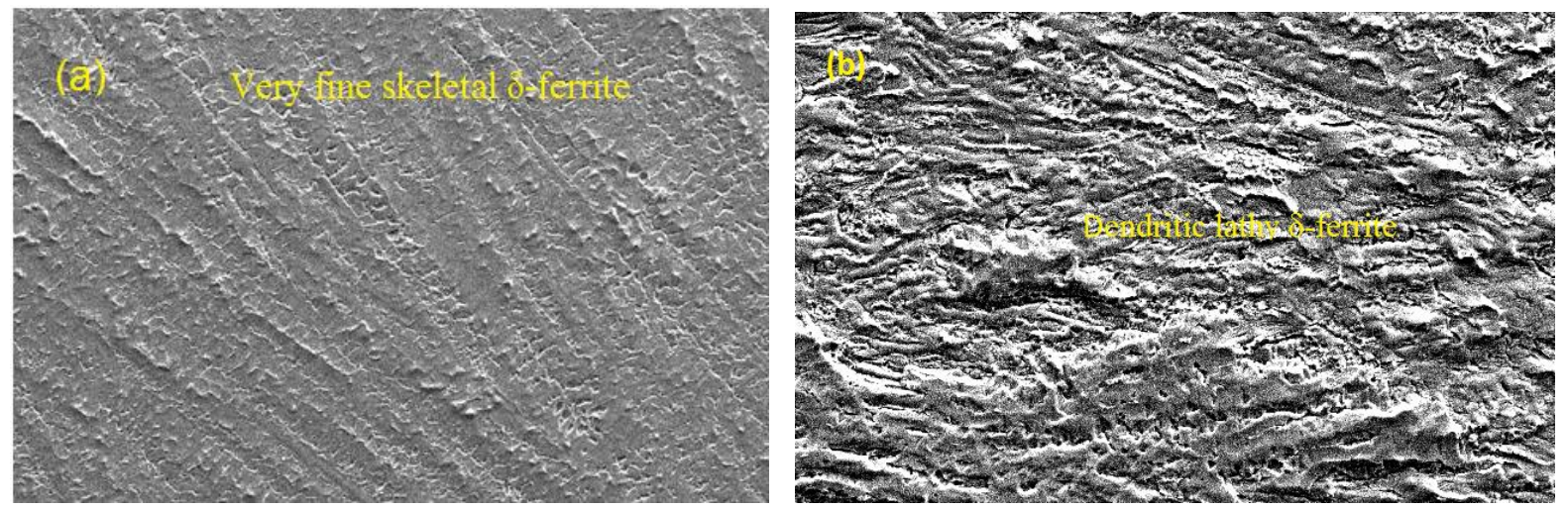

Fig. 8 SEM micrographs of weld metals (a) sample no.14 (b) sample no. 7

\subsection{Micro-hardness analysis}

Microstructural analysis being done, the micro-hardness test has been conducted by Vickers's micro-hardness testing machine (Make: MATSUZAWA; Model: AMT-X7BFS) on etched transverse cross section of the welded specimens using a load of $100 \mathrm{~g}$, which is applied for duration of 10s. Fig.9 represents the micro-hardness profile of two welded samples i.e. sample no. 14 and sample no.7. It is noticed that both the welded joints show higher the micro-hardness value at weld zone/ fusion zone with respect to the base metal and HAZ zone. Similar result has been reported by buddu et.al. [26] and Kumar et.al. [27]. The micro hardness value increases towards the fusion zone as the indenter passes from base metal to weld center. Sample no.14 depicts the highest hardness value and sample no. 7 shows the lowest hardness value in the weld zone. The variation in hardness values in different weld samples may be induced by their microstructure refinement due to the quick solidification of the weld pool. The weld sample no. 7 has lower $\delta$-ferrite content and relatively coarse grain structure. The sample no.14 having relatively higher hardness values due to higher $\delta$-ferrite content and having relatively finer grain structure.

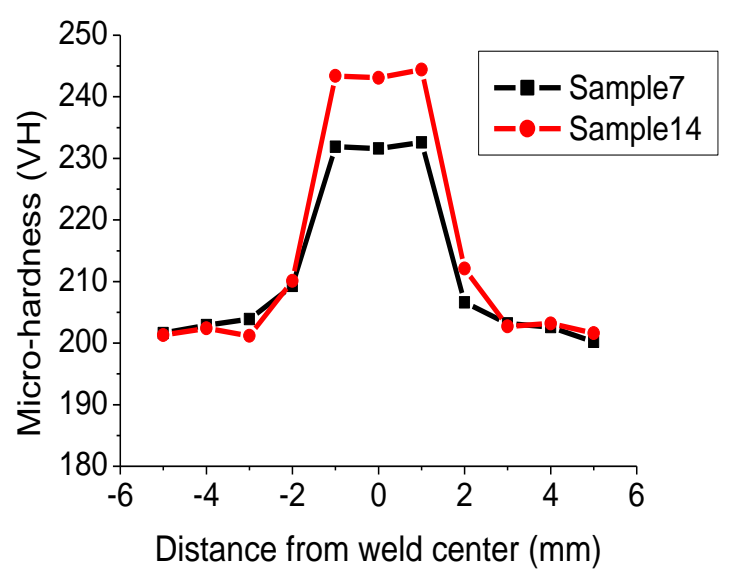

Fig. 9 Micro-hardness plots of sample $7 \& 14$

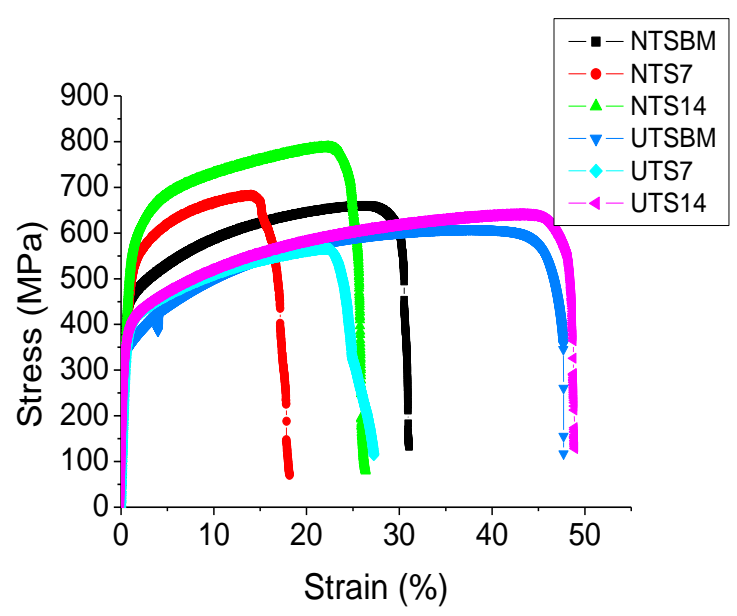

Fig. 10 Stress-strain curves of BM \& WM

\subsection{Tensile Properties}

The uniaxial tensile test of all the welded samples along with base metal has been carried out to evaluate the joint strength both in notched and unnotched method at room temperature. Three tensile tests have been conducted for each condition of welding input parameters and average NTS and UTS are tabulated in Table 3. Again, stress-strain curve for both NTS and 
UTS specimens of selected welded joints along with base metals is also shown in Fig. 10. All the welded samples are fractured at HAZ-base interface and the base metal is fractured at the centre of the gauge length. It is found that sample no. 7 shows minimum joint strength in both cases i.e. NTS and UTS. Whereas sample no. 14 depicts maximum joint strength in both cases i.e. NTS and UTS. The notch strength ratio (NSR) is also calculated as the ratio of notched tensile strength to unnotched / smooth tensile strength and tabulated in the Table 3. It is found that the NSR is greater than unity for all the welded joints, even for base metal also. This indicates that the TIG welded joints are insensitive to notches or geometric discontinuities and this implies that AISI 316L welded joints fall under "notch ductile materials" category. The sample no. 14 exhibits much higher tensile strength and higher ductility than others due to formation of very fine skeletal $\delta$-ferrite grains in the weld region, moderate precipitation and smaller dendrite size. The reason of lowest tensile strength obtained by sample no. 7 is formation of coarse grains structure in the weld zone and higher dendrite size. This is in line with the micro-hardness data.

\subsection{Developing the mathematical model: regression analysis}

In the present investigation Design-Expert 11 software has been applied to the experimental data to obtain the quadratic mathematical equations for NTS and UTS. This regression equations/ mathematical model are used for predicting responses (NTS and UTS) in terms of current, speed and gas flow rate. It consists of the effect of main parameters and first order interaction of all parameters.

\subsubsection{Notched tensile strength}

In the present study responses, NTS and UTS are function of TIG welding current (A), travel speed (B) and gas flow rate (C). Typically, a second order polynomial equation is used in RSM that is provided below:

$$
\mathrm{Y}=b_{0}+\sum_{i=1}^{k}\left(b_{i} x_{i}\right)+\sum_{i=1}^{k}\left(b_{i i} x_{i}^{2}\right)+\sum \sum\left(b_{i j} x_{i} x_{j}\right)+€
$$

where $\mathrm{Y}=$ response variables i.e. dependent variables

$x_{i}=$ predicted variables i.e. independent variables

$b_{0}=$ model constant

$€=$ random error

parameters $b_{i}, b_{i i}, b_{i j}$ are known as regression coefficient, where $\mathrm{i}=1,2,3, . . \mathrm{k}$ and $\mathrm{j}=1,2$, $3, \ldots \mathrm{k}$.

In the study three parameters have been considered. Therefore for 3 factors, the selected polynomial equations can be provided as:

$$
\begin{gathered}
\sigma=b_{0}+\mathrm{b}_{1}(\mathrm{~A})+\mathrm{b}_{2}(\mathrm{~B})+b_{3}(\mathrm{C})+b_{11} A^{2}+b_{22} B^{2}+b_{33} C^{2}+ \\
b_{12}(\mathrm{AB})+b_{13}(\mathrm{AC})+b_{23}(\mathrm{BC})
\end{gathered}
$$

where $\sigma$ is the predicted response, $b_{0}$ model constant, $b_{1}, b_{2}$ and $b_{3}$ linear coefficients, $b_{11}, b_{22}$ and $b_{33}$ quadratic coefficients and $b_{12}, b_{13}$ and $b_{23}$ cross interaction coefficients.

The second order regression equation for the response, notched tensile strength is developed by using RSM, in terms of coded factors are given below:

$$
\begin{aligned}
\sigma_{\mathrm{NTS}}=776.38 & +11.50 \mathrm{~A}-9.32 \mathrm{~B}-13.70 \mathrm{C}-25.50 \mathrm{~A}^{*} \mathrm{~A}-31.36 \mathrm{~B} * \mathrm{~B}- \\
& -18.89 \mathrm{C} * \mathrm{C}+12.47 \mathrm{~A} * \mathrm{~B}+26.10 \mathrm{~A}^{*} \mathrm{C}+17.53 \mathrm{~B} * \mathrm{C}
\end{aligned}
$$


Table 4 shows the adequate ANOVA test results for NTS and it is found that model is significant $(\mathrm{P}<0.05)$ at $95 \%$ confidence level or $5 \%$ significant level. The lack of fit value of the model is not significant which is desirable. The model F-value is 55.71 which indicate that the model is significant. Here A, B, C, $\mathrm{A}^{2}, \mathrm{~B}^{2}, \mathrm{C}^{2}, \mathrm{~A} \times \mathrm{B}, \mathrm{A} \times \mathrm{C}$, and $\mathrm{B} \times \mathrm{C}$ are the significant model terms. The ' $\mathrm{R}^{2}$ ' value is 0.9901 and 'Pred $\mathrm{R}^{2}$ ' of 0.9202 is in reasonable agreement

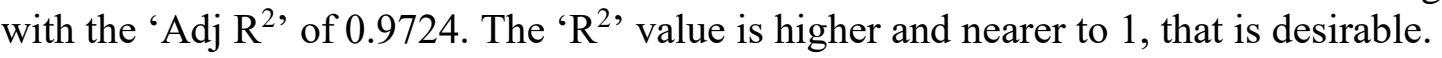

Table 4 ANOVA results for testing adequacy of the NTS

\begin{tabular}{|c|c|c|c|c|c|c|}
\hline Source & Sum of Squares & $\mathrm{df}$ & Mean Square & F-value & $\mathrm{p}$-value & Remarks \\
\hline Model & 14261.32 & 9 & 1584.59 & 55.71 & 0.0002 & significant \\
\hline A-Current & 1058.23 & 1 & 1058.23 & 37.20 & 0.0017 & significant \\
\hline B-Speed & 694.53 & 1 & 694.53 & 24.42 & 0.0043 & Significant \\
\hline C-GFR & 1500.70 & 1 & 1500.70 & 52.76 & 0.0008 & Significant \\
\hline $\mathrm{AB}$ & 621.50 & 1 & 621.50 & 21.85 & 0.0055 & Significant \\
\hline $\mathrm{AC}$ & 2725.36 & 1 & 2725.36 & 95.81 & 0.0002 & Significant \\
\hline $\mathrm{BC}$ & 1229.90 & 1 & 1229.90 & 43.24 & 0.0012 & Significant \\
\hline $\mathrm{A}^{2}$ & 2400.37 & 1 & 2400.37 & 84.39 & 0.0003 & Significant \\
\hline $\mathrm{B}^{2}$ & 3631.10 & 1 & 3631.10 & 127.65 & $<0.0001$ & Significant \\
\hline $\mathrm{C}^{2}$ & 1317.13 & 1 & 1317.13 & 46.30 & 0.0010 & significant \\
\hline Residual & 142.22 & 5 & 28.44 & & & \\
\hline Lack of Fit & 60.37 & 3 & 20.12 & 0.4916 & 0.7235 & not significant \\
\hline Pure Error & 81.86 & 2 & 40.93 & & & \\
\hline Cor Total & 14403.54 & 14 & & & & \\
\hline
\end{tabular}

\subsubsection{Unnotched tensile strength}

The second order regression equation for the response, UTS in terms of coded factors are given below:

$$
\begin{aligned}
\sigma_{\mathrm{UTS}}=640.58 & +6.24 \mathrm{~A}+3.36 \mathrm{~B}-9.24 \mathrm{C}-14.77 \mathrm{~A} * \mathrm{~A}-8.71 \mathrm{~B} * \mathrm{~B}- \\
& -19.69 \mathrm{C} * \mathrm{C}+4.65 \mathrm{~A} * \mathrm{~B}+9.36 \mathrm{~A} * \mathrm{C}+7.84 \mathrm{~B} * \mathrm{C}
\end{aligned}
$$

The adequacy of the developed model for UTS has been tested using the statistical analysis of variance (ANOVA) technique. Table 5 shows the adequate ANOVA test results for UTS. From table it is found that the regression is significant with linear and quadratic terms for UTS at $95 \%$ confidence level as its p-value is less than 0.05 . The lack of fit value of the model is not significant which is desirable. The model indicates that the welding process parameters: current (A), speed (B) and gas flow rate (C), and its squared terms [current $\mathrm{x}$ current $\left(\mathrm{A}^{2}\right)$, speed $\mathrm{x}$ speed $\left(\mathrm{B}^{2}\right)$ and gas flow rate $\mathrm{x}$ gas flow rate $\left(\mathrm{C}^{2}\right)$ ] and interaction effects [current and speed $(\mathrm{A} \times \mathrm{B})$, current and gas flow rate $(\mathrm{A} \times \mathrm{C})$ and speed and gas flow rate $(\mathrm{B} \times$ C)], have significant effect on UTS. The ' $R^{2}$ ' value is 0.9943 and 'Pred $R^{2}$ ' of 0.9300 is in reasonable agreement with the 'Adj $\mathrm{R}^{2}$ ' of 0.9839 . The ' $\mathrm{R}^{2}$ ' value is higher and nearer to 1 , that is desirable.

The ANOVA result indicates that the gas flow rate is the most significantly factor effects unnotched tensile strength followed by welding current and speed. 
Table 5 ANOVA results for testing adequacy of the UTS

\begin{tabular}{|lcccccc|}
\hline \hline \multicolumn{1}{c}{ Source } & Sum of Squares & df & Mean Square & F-value & p-value & Remarks \\
\hline Model & 3997.98 & 9 & 444.22 & 96.12 & $<0.0001$ & significant \\
A- Current & 311.38 & 1 & 311.38 & 67.38 & 0.0004 & Significant \\
B- Speed & 90.12 & 1 & 90.12 & 19.50 & 0.0069 & Significant \\
C-Gas flow rate & 683.76 & 1 & 683.76 & 147.96 & $<0.0001$ & Significant \\
AB & 86.49 & 1 & 86.49 & 18.72 & 0.0075 & Significant \\
AC & 350.25 & 1 & 350.25 & 75.79 & 0.0003 & Significant \\
BC & 246.02 & 1 & 246.02 & 53.24 & 0.0008 & Significant \\
A $^{2}$ & 805.03 & 1 & 805.03 & 174.20 & $<0.0001$ & Significant \\
$\mathrm{B}^{2}$ & 280.17 & 1 & 280.17 & 60.63 & 0.0006 & Significant \\
$\mathrm{C}^{2}$ & 1431.98 & 1 & 1431.98 & 309.87 & $<0.0001$ & significant \\
Residual & 23.11 & 5 & 4.62 & & & \\
Lack of Fit & 16.69 & 3 & 5.56 & 1.73 & 0.3862 & not significant \\
Pure Error & 6.42 & 2 & 3.21 & & & \\
Cor Total & 4021.09 & 14 & & & \\
\multicolumn{2}{r}{$R^{2}=0.9943$, Adjusted $R^{2}=0.9839$, Predicted $R^{2}=0.9300$, Adeq Precision = 33.7848 }
\end{tabular}

\subsubsection{Model validation}

The soundness of the developed model has also been checked by the normal probability plot of the residuals for NTS and UTS as shown in Fig. 11(a) and Fig. 11(b) respectively. From figure it is seen that the residuals fall on the straight line, which means the errors are distributed normally and the mathematical relationship is correctly developed.
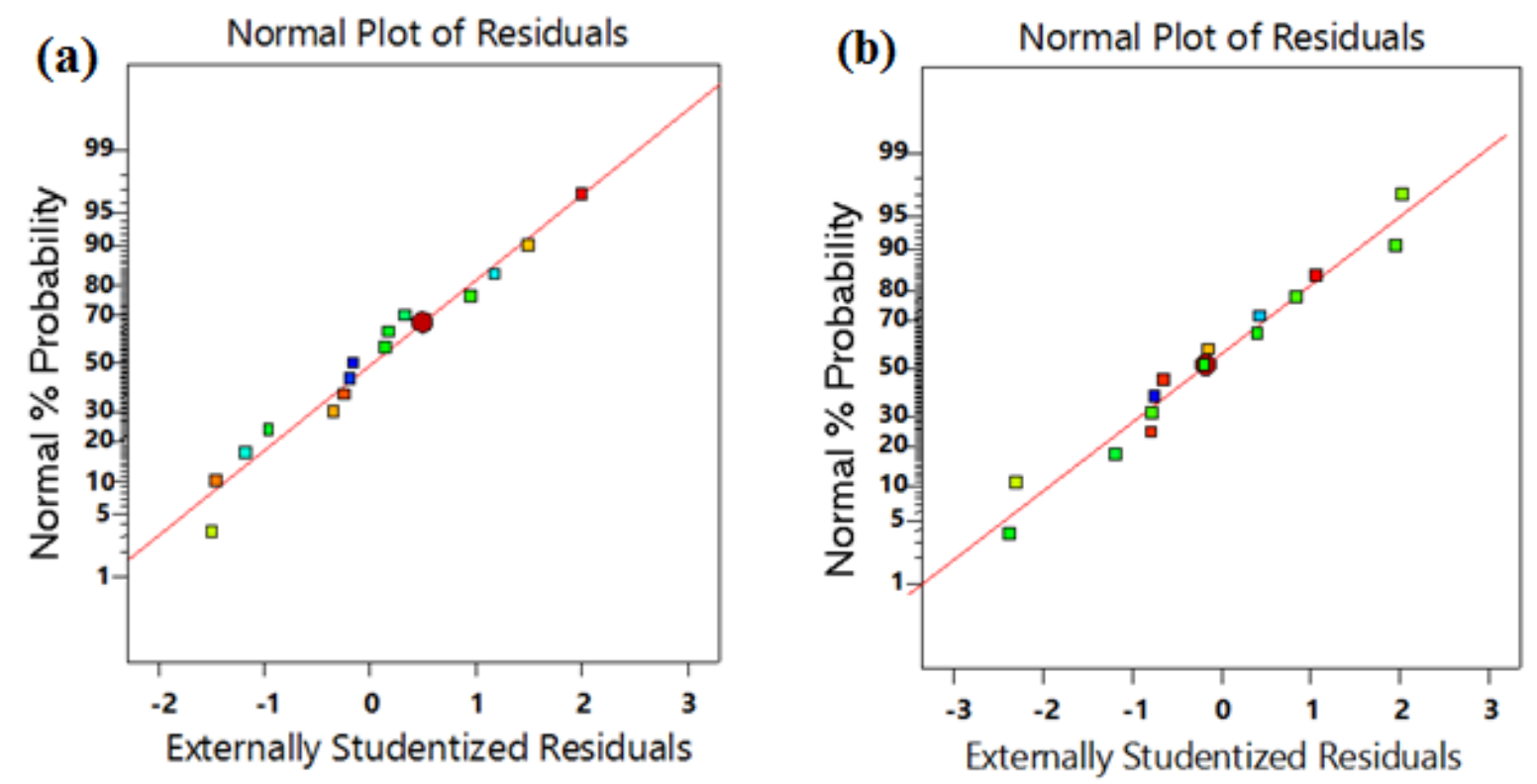

Fig. 11: Residual plot of (a) NTS (b) UTS

Fig. 12 (a-b) shows the comparison between the predicted and the actual values of response variables (NTS and UTS). The graphs indicate that the developed models are adequate. It also suggests that the predicted results are in good agreement with measured data. 

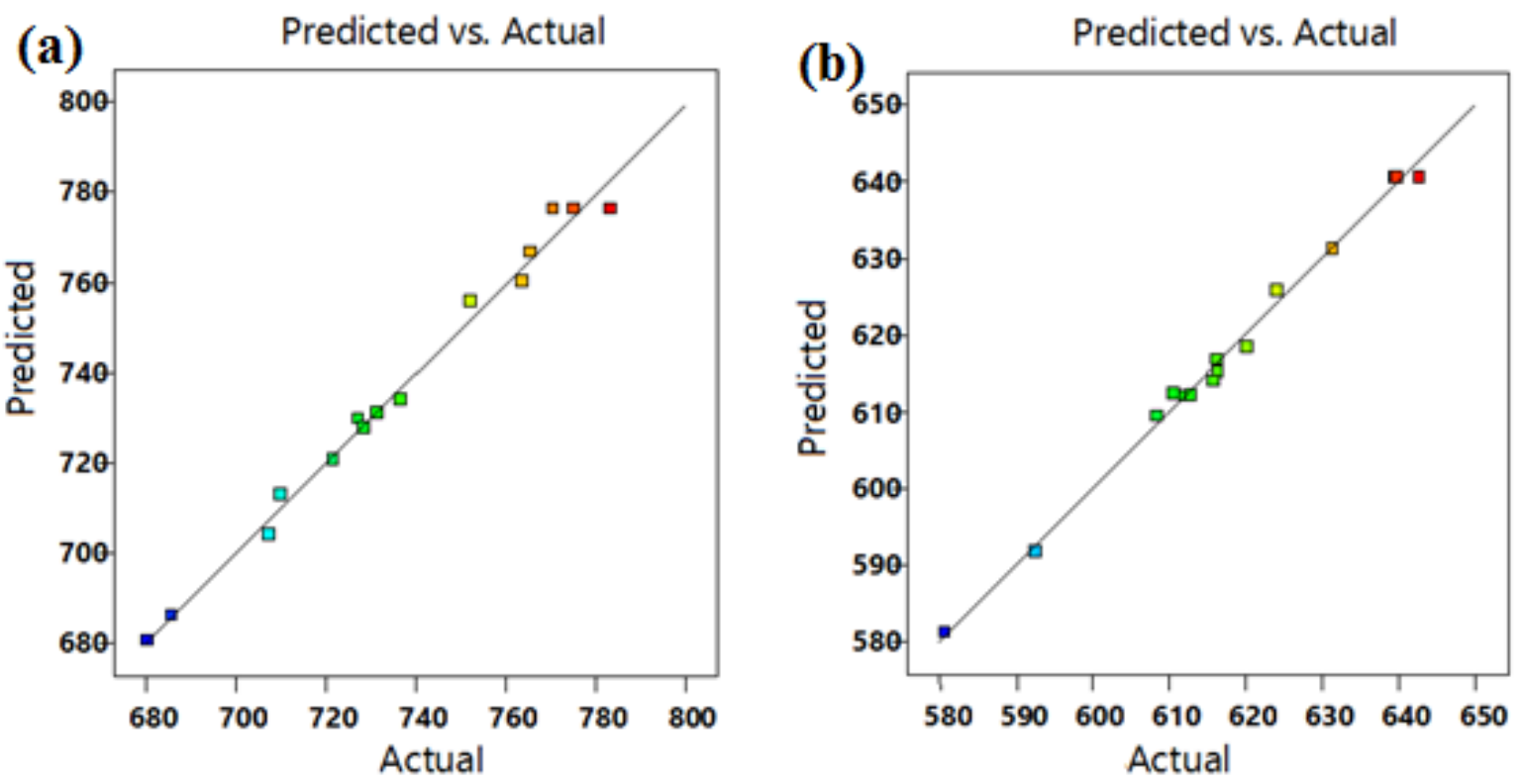

Fig. 12 Predicted vs actual plot of (a) NTS and (b) UTS

\subsubsection{Effect of the process parameters on notch tensile strength}

The response surface and contour plots have been drawn from the Eq.3 to study the interaction effects of process parameters on NTS and shown in Figs. 13-14. Figs. 13(a) \& 14(a) show the joint effect of welding speed and welding current on NTS. It is noticed that, tensile strength first increases steadily then decreases with further increasing in the levels of the welding current. The NTS is found to be maximum at the medium levels of welding current and speed. Figs. 13(b) \& 14(b) represent the combined outcome of gas flow rate and welding current on NTS. It is found that NTS increases with GFR up to a threshold value and thereafter it stars decreasing to its minimum value. NTS is maximum at medium values of GFR and welding current. This is due to the fact that at low GFR, contamination may occur and lack of penetration may be due to low current/low heat input. Therefore a weak joint is formed. Further increasing in the level of GFR, as well as welding current towards the centre value, the NTS is found to be improved and attained its maximum value at center point. While increasing in the level of GFR above the centre value, it creates turbulence and swirling currents that pull in airborne contaminations and high current means high heat input and this may to decomposition of base metal as a result of low joint strength. Figs. 13(c) \& 14(c) show the interaction plot between the GFR and welding speed on the NTS. It is observed that the NTS is optimum at the center value of GFR and welding speed. At low welding speed the heat input is high and it causes overheating of base metal and produces low strength joint. The study suggests that it is not recommended to employ very upper or lower level of TIG welding process parameters for obtaining optimal value of tensile strength. Gas flow rate is the most significant factor on NTS and it is followed by welding current and speed. 

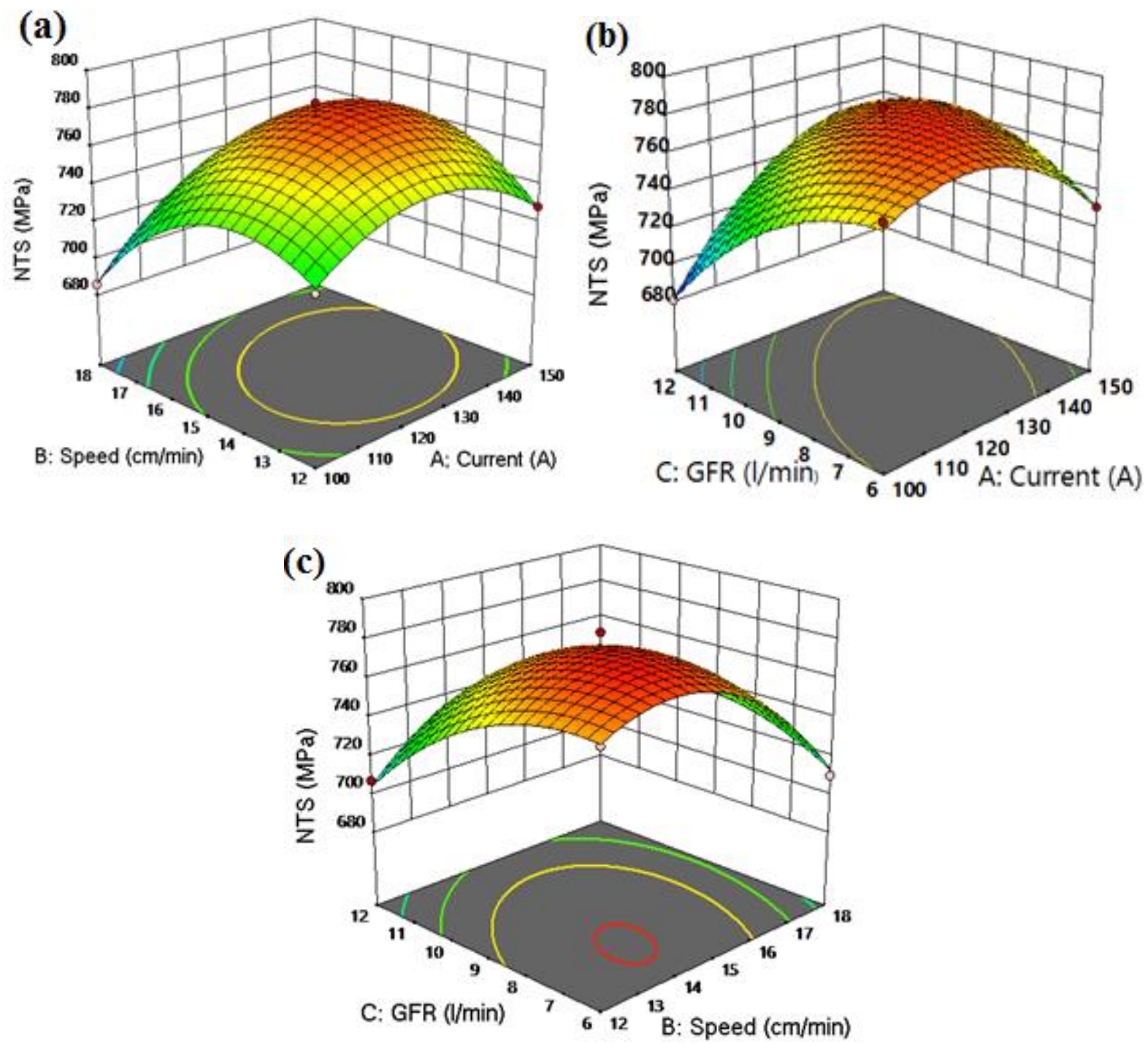

Fig. 13 Response surface plots showing the interaction effects of (a) speed vs current, (b) GFR vs current and (c) GFR vs speed on NTS
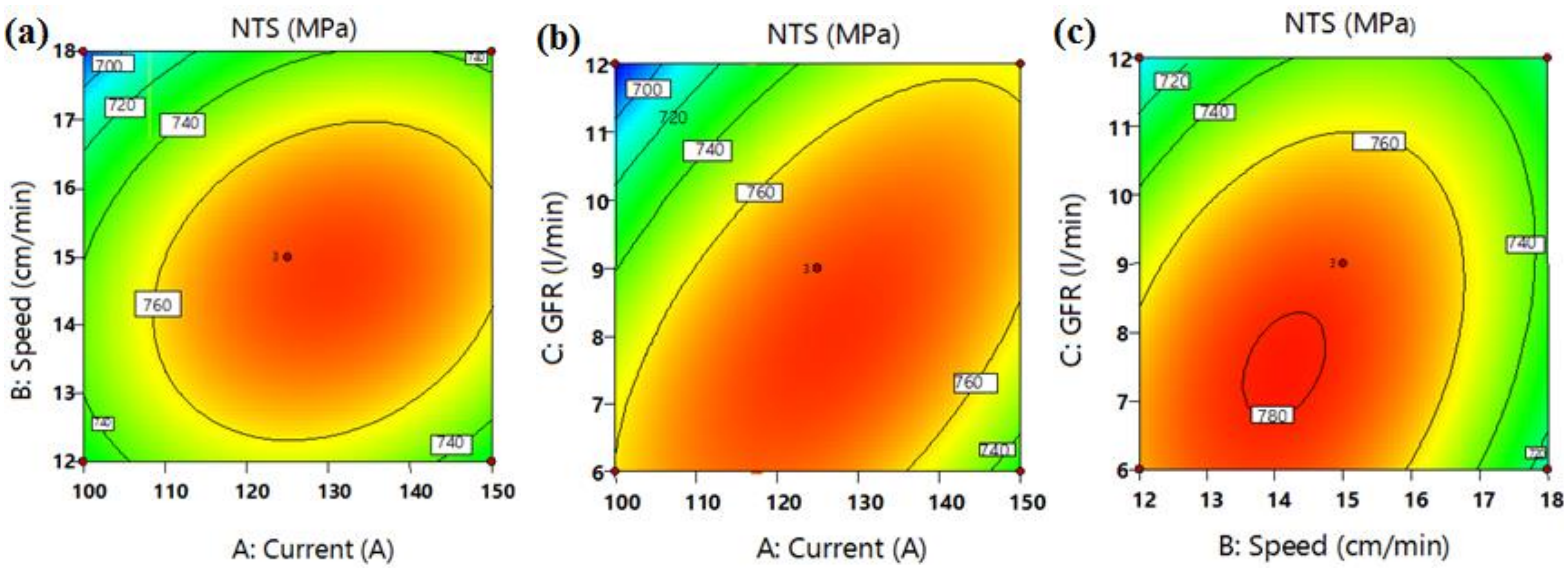

Fig. 14 Contour plots showing the interaction effects of (a) speed vs current, (b) GFR vs current and (c) GFR vs speed on NTS 


\subsubsection{Effect of the process parameters on unnotched tensile strength}

Figs. 15-16 illustrate the response surface plots and contour plots to study the interaction effects of input process parameters on UTS. Similar type of patterns is also observed in case of UTS. It is noticed that, UTS first increases gradually with increase of welding input parameters up to a threshold value and thereafter it stars decreasing. UTS is optimum at the medium values of welding current, GFR and welding speed. At low welding speed means high heat input, results in slow cooling rate and it will take longer time for solidification. As a result it produces coarse grain, hence low tensile strength. Gas flow rate is the most significant factor on UTS and it is followed by welding current and speed.
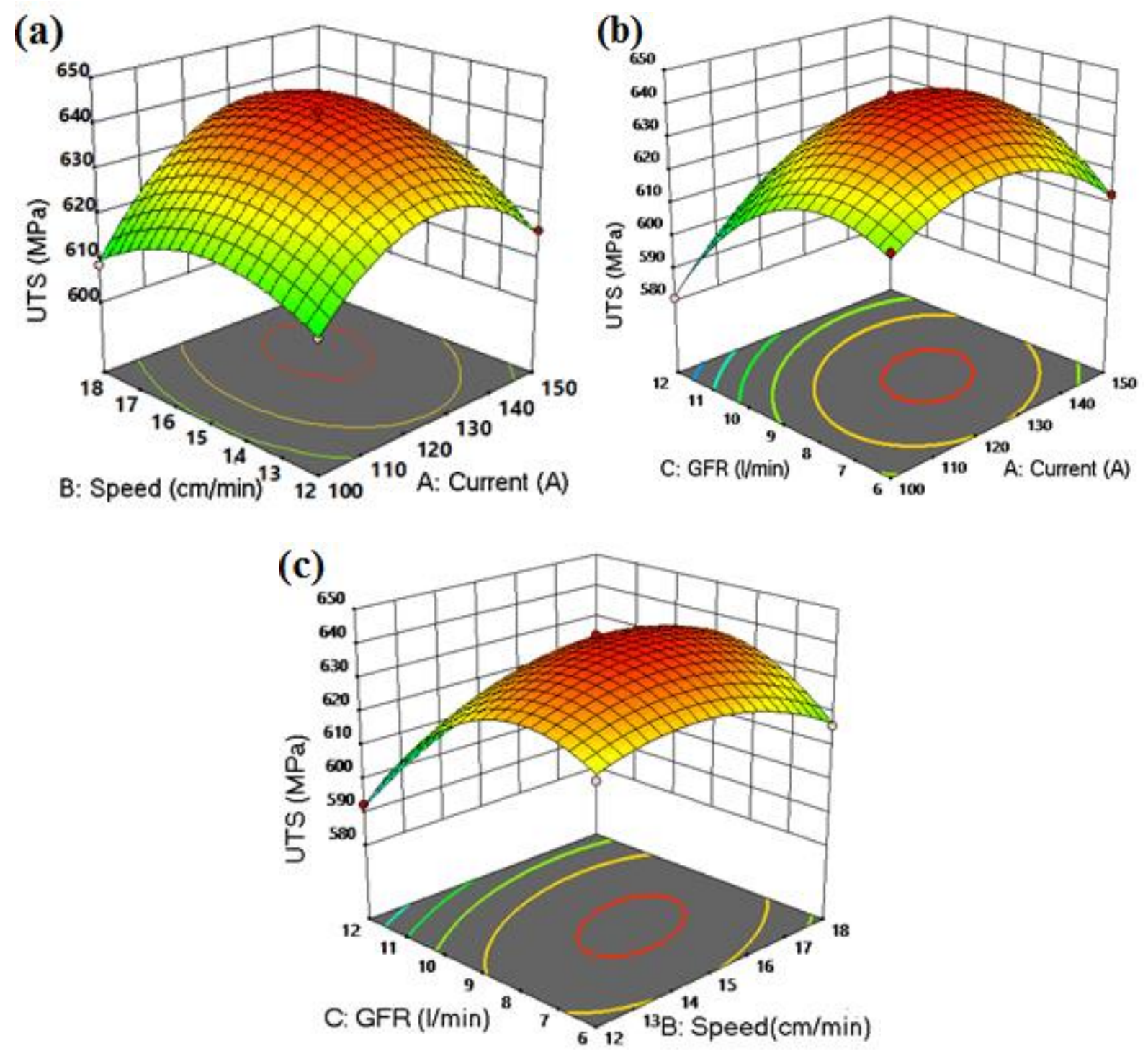

Fig. 15 Response surface plots showing the interaction effects of (a) speed vs current, (b)

GFR vs current and (c) GFR vs speed on UTS 

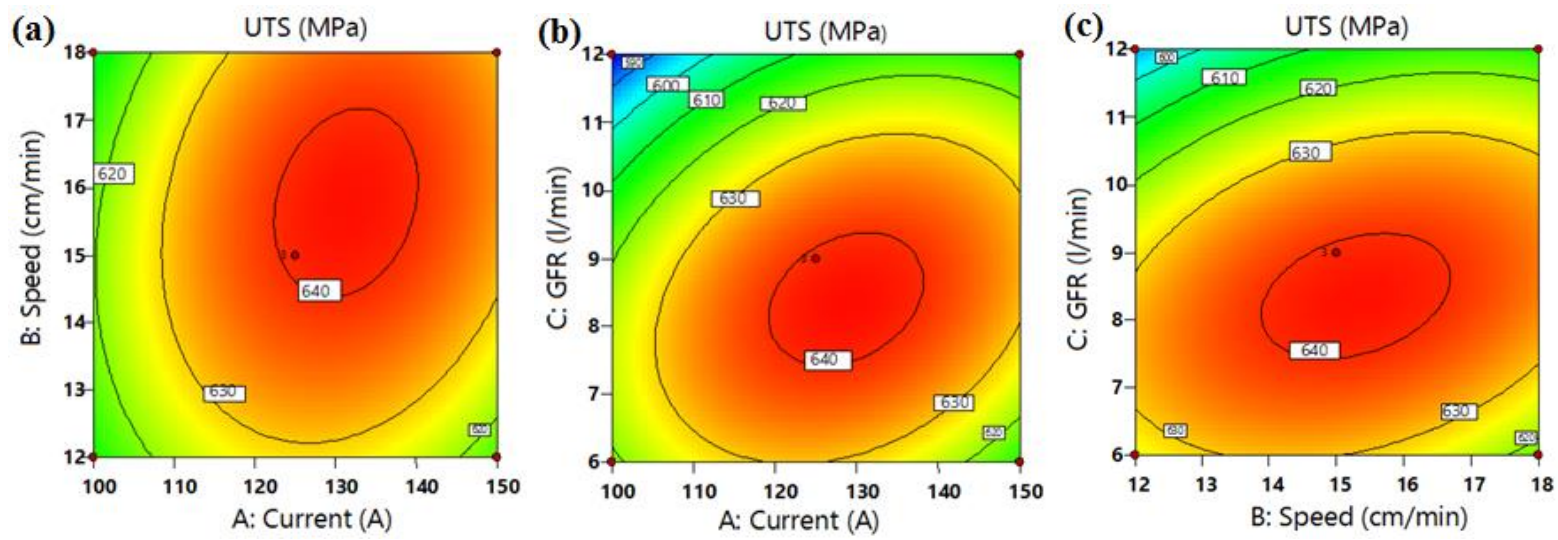

Fig. 16 Contour plots showing the interaction effects of (a) speed vs current, (b) GFR vs current and (c) GFR vs speed on UTS

\section{$4 \quad$ Numerical optimization}

The objective of the present study is to determine the optimum parametric setting to attain maximum tensile strength, not only NTS but also UTS of welded specimens simultaneously which is desirable for good quality of welded joint. The desirability function analysis is applied to get an optimum parametric setting to attain maximum NTS and UTS of welded specimens simultaneously. Minitab v17 software is used for optimization of TIG welding process. The usual steps and procedures are followed which is incorporated in Minitab software, the details of these are omitted here. The results of multi objective optimization for NTS and UTS are shown in Fig. 17. The optimum NTS: $780.15 \mathrm{MPa}$ and UTS: $641.44 \mathrm{MPa}$ have been obtained at welding current of 126.77A, welding speed at $14.61 \mathrm{~cm} / \mathrm{min}$ and shielding gas flow rate of $8.12 \mathrm{l} / \mathrm{min}$. The value of composite desirability factor $\mathrm{D}$ is 0.9752 .

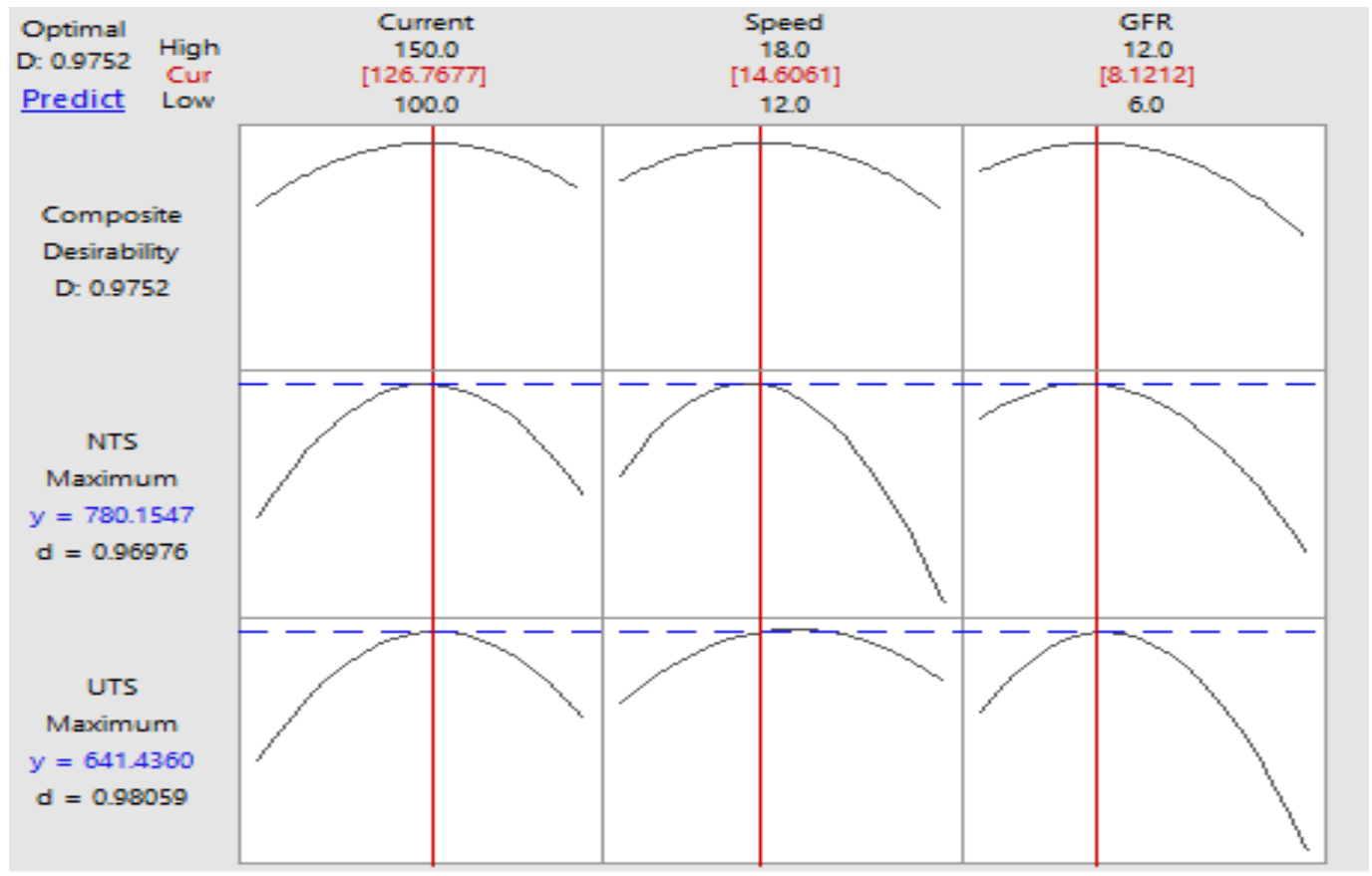

Fig. 17 Optimization results of NTS and UTS 


\subsection{Confirmation test}

The results of optimization obtained have been validated by performing confirmatory experiments. Table 6 represents the results of confirmatory tests that are conducted at optimum conditions. It is noticed from table that the error in terms of percentage between the predicted and experimental results is very small and less than $1 \%$. This indicates that the optimized TIG welding process parameters can be considered to obtained higher NTS and UTS of 316L stainless steel.

Table 6 Multi-objective optimization results

\begin{tabular}{|cccccc|}
\hline \multicolumn{3}{|c}{ Optimum condition } & \multicolumn{2}{c|}{ Responses } \\
\hline $\mathrm{A}(\mathrm{A})$ & $\mathrm{B}(\mathrm{cm} / \mathrm{min})$ & $\mathrm{C}(\mathrm{l} / \mathrm{min})$ & & NTS (MPa) & UTS (MPa) \\
\hline 126.77 & \multirow{2}{*}{14.61} & \multirow{2}{*}{8.12} & Avg. Actual & 785.23 & 645.56 \\
& & & Predicted & 780.15 & 641.44 \\
& & & | Error \% | & 0.65 & 0.64 \\
\hline
\end{tabular}

\section{CONCLUSIONS}

Within the scope and objective of the present work, the following conclusions are drawn in respective of TIG welded joints of AISI 316L stainless steel, based on experimental results and analysis:

$>$ The most significant factor affecting not only NTS but also UTS is gas flow rate. Next important factor in this respect is welding current followed by welding speed.

$>$ The NSR is found to be greater than unity for all the welded joints and this indicates that the TIG welded joints are insensitive to notches or geometric discontinuities.

$>$ Sample no.14 shows the highest tensile strength and this is due to formation of very fine skeletal $\delta$-ferrite grains in the weld region, moderate precipitation.

$>$ The micro-hardness value of the weld metal is found to be remarkably higher as compare to those of HAZ zone and base metal. It is also found that almost all the welded joints exhibit higher tensile strength than that of the base metal.

$>$ An optimum NTS of $780.15 \mathrm{MPa}$ and UTS of $641.44 \mathrm{MPa}$ are obtained under the welding conditions of current at $126.77 \mathrm{~A}$, welding speed at $14.61 \mathrm{~cm} / \mathrm{min}$ and gas flow rate at $8.12 \mathrm{l} / \mathrm{min}$.

$>$ The percentage error between the predicted results and the results of confirmatory test is found to be less than $1 \%$ which validates the applied optimization method.

\section{ACKNOWLEDGEMENT}

The authors would like to acknowledge Professor (Dr.) D. Bose, Mechanical Engineering Department, National Institute of Technical Teachers Training and Research, Kolkata, West Bengal, for providing welding set up for experiment for the present research work.

\section{REFERENCES}

[1] N. Ghosh, P. K. Pal, G. Nandi, R. Rudrapati, Parametric optimization of gas metal arc welding process by PCA based Taguchi method on austenitic stainless steel AISI 316L. Materials Today: Proceedings 2018 (5), No. 1, 1620 - 1625.

[2] Y. S. Tarng, W. H. Yang. Optimisation of the weld bead geometry in gas tungsten arc welding by the Taguchi method. The International Journal of Advanced Manufacturing Technology 1998 (14), No. 8, 549 - 554. 
[3] S. C. Juang, Y. S. Tarng. Process parameter selection for optimizing the weld pool geometry in the tungsten inert gas welding of stainless steel. Journal of Materials Processing Technology 2002 (122), No. 1, 33 - 37.

[4] S. C. Bodkhe, D. R. Dolas. Optimization of activated tungsten inert gas welding of 304L austenitic stainless steel. Procedia Manufacturing 2018 (20), 277 - 282.

[5] A. Handa, V. Chawla. Experimental evaluation of mechanical properties of friction welded dissimilar steels under varying axial pressures. Journal of Mechanical Engineering - Strojnícky časopis 2016 (66), No 1, 27 - 36.

[6] M. Ragavendran, N. Chandrasekhar, R. Ravikumar, R. Saxena, M. Vasudevan, A. K. Bhaduri. Optimization of hybrid laser - TIG welding of 316LN steel using response surface methodology (RSM). Optics and Lasers in Engineering 2017 (94), 27 - 36.

[7] P. Élesztős, R. Jančo, V. Voštiar. Optimization of welding process using a genetic algorithm. Journal of Mechanical Engineering - Strojnícky časopis 2018 (68), No 2, 17 -24 .

[8] D. Santha Rao, N. Ramanaiah. Process parameters optimization for producing AA6061/TiB ${ }_{2}$ composites by friction stir processing, Journal of Mechanical Engineering - Strojnícky časopis 2017 (67), No. 1, 101 - 118.

[9] K. Y. Benyounis, A. G. Olabi, Optimization of different welding processes using statistical and numerical approaches - A reference guide. Advances in Engineering Software 2008 (39), No. 6, 483 - 496.

[10] V. Gunaraj, N. Murugan. Application of response surface methodology for predicting weld bead quality in submerged arc welding of pipes. Journal of Materials Processing Technology 1999 (88), 266 - 275.

[11] A. Kumar, S. Sundarrajan. Optimization of pulsed TIG welding process parameters on mechanical properties of AA 5456 Aluminum alloy weldments. Materials and Design 2009 (30), No. 4, 1288 - 1297.

[12] N. Murugan, R. S. Parmer. Effects of MIG process parameters on the geometry of the bead in the automatic surfacing of stainless steel. Journal of Materials Processing Technology 1994 (41), No. 4, 381 - 398.

[13] G. Padmanaban, V. Balasubramanian. Optimization of laser beam welding process parameters to attain Maximum tensile strength in AZ31B magnesium alloy. Optics \& Laser Technology 2010 (42), No. 8, 1253 - 1260.

[14] C. Y. Chu, C. T. Hsieh, L. W. Tsay. Microstructure and notched tensile fracture of Ti6Al-4V to Ti-4.5Al-3V-2Fe-2Mo dissimilar welds. Materials and Design 2014 (63), 14 $-19$.

[15] E. M. Anawa, A. G. Olabi. Optimization of tensile strength of ferritic/austenitic laser welded components. Optics and Lasers in Engineering 2008 (46), No. 8, 571 - 577.

[16] S. Rajakumar, C. Muralidharan, V. Balasubramanian. Influence of friction stir welding process and tool parameters on strength properties of AA7075- $\mathrm{T}_{6}$ aluminium alloy joints. Materials and Design 2011 (32), No. 2, 535 - 549.

[17] S. T. Selvamani, K. Palanikumar. Optimizing the friction welding parameters to attain maximum tensile strength in AISI 1035 grade carbon steel rods. Measurement 2014 (53), $10-21$. 
[18] S. Srivastava, R. K. Garg. Process parameter optimization of gas metal arc welding on IS:2062 mild steel using response surface methodology. Journal of Manufacturing Processes 2017 (25), 296 - 305.

[19] N. Ghosh, P. K. Pal, G. Nandi. Parametric optimization of MIG welding on 316L austenitic stainless steel by Grey - Based Taguchi method. Procedia Technology 2016 (25), $1038-1048$.

[20] A. K. Lakshminarayanan, K. Shanmugam, V. Balasubramanian. Effect of welding processes on tensile and impact properties, hardness and microstructure of AISI 409M ferritic stainless joints fabricated by duplex stainless steel filler metal. Journal of iron and steel research, International 2009 (16), No. 5, 66 - 72.

[21] T. Senthil Kumar, V. Balasubramanian, M. Y. Sanavullah. Influences of pulsed current tungsten inert gas welding parameters on the tensile properties of AA 6061 aluminium alloy. Materials \& Design 2007 (28), No. 7, 2080 - 2092.

[22] Jau-Wen Lin, Hsi-Cherng Chang, Ming-Hsiu Wu. Comparison of mechanical properties of pure copper welded using friction stir welding and tungsten inert gas welding. Journal of Manufacturing Processes 2014 (16), No. 2, 296 - 304.

[23] N. Ghosh, R. Rudrapati, P. K. Pal, N. Goutam. Parametric optimization of gas metal arc welding process by using Taguchi method on ferritic stainless steel AISI 409. Materials Today: proceedings 2017 (4), No. 2, 2213 - 2221.

[24] C. Wichan, S. Loeshpahn. Effect of filler alloy on microstructure, mechanical and corrosion behaviour of dissimilar weldment between AISI 201 stainless steel and low carbon steel sheets produced by a gas tungsten arc welding. Advanced Materials Research 2012 (581-582), $808-816$.

[25] J. C. Lippold, D. J. Kotechi. Welding metallurgy and weldability of stainless steels, A John Wiley \& Sons, Inc., Hoboken, New Jersey 2005, 29 - 31.

[26] R. K. Buddu, N. Chauhan, P.M. Raole. Mechanical properties and microstructural investigations of TIG welded $40 \mathrm{~mm}$ and $60 \mathrm{~mm}$ thick SS 316L samples for fusion reactor vacuum vessel applications. Fusion Engineering and Design 2014 (89), No. 12, $3149-3158$.

[27] N. Kumar, M. Mukherjee, A. Bandyopadhyay. Study on laser welding of austenitic stainless steel by varying incident angle of pulsed laser beam. Optics and Laser Technology 2017 (94), 296 - 309. 